\title{
Switching bipolar disorder patients treated with clozapine to another antipsychotic medication: a mirror image study
}

This article was published in the following Dove Press journal:

Neuropsychiatric Disease and Treatment

23 January 2017

Number of times this article has been viewed

Petru Ifteni ${ }^{1,2}$

Andreea Teodorescu ${ }^{1,2}$

Marius Alexandru Moga'

Alina Mihaela Pascu'

Roxana Steliana Miclaus ${ }^{1,2}$

'Faculty of Medicine, Transilvania University of Brasov, Brasov, Romania; ${ }^{2}$ Clinical Hospital of Psychiatry and Neurology Brasov, Brasov, Romania
Correspondence: Andreea Teodorescu Faculty of Medicine, Transilvania University of Brasov, 29 Eroilor Bulevard, Brasov, Romania

Email andre_martie@yahoo.com
Abstract: Bipolar disorder (BD) is associated with periodic symptom exacerbations, leading to functional impairment, and increased risk of suicide. Although clozapine has never been approved for the treatment of BD, it is occasionally used in severe mania. The aim of the study is to evaluate the risks and benefits of switching clozapine in remitted BD patients. This is an observational, mirror image study of 62 consecutive remitted BD outpatients treated with clozapine. Twenty-five patients were switched to another antipsychotic following a change in a drug reimbursement rule, while 37 continued on clozapine. The mean time in remission was shorter for the switched group ( $9.2 \pm 4$ months vs $13 \pm 6$ months, $P=0.018)$, and the number of patients who relapsed was larger ( $\mathrm{n}=21$ vs $\mathrm{n}=8, P<0.0001$ ). The results suggest that switching from clozapine to another antipsychotic may increase the risk of relapses in remitted patients with BD.

Keywords: clozapine, bipolar disorder, relapse, switch, cost

\section{Background}

Bipolar disorder (BD) is associated with recurrent exacerbation of manic, depressed or mixed episodes, leading to functional impairment, substance abuse, risk of suicide, accidents, and increased cost of care. ${ }^{1-6}$ Antipsychotics are a proven option in the treatment of BD. ${ }^{7-11}$ Although clozapine has never been approved for the treatment of bipolar disorder, it has showed efficacy in acute mania with psychosis and for the treatment of refractory symptoms associated with BD. ${ }^{12-16}$

The efficacy of clozapine in severe manic patients was reported both as monotherapy and as an add-on strategy. ${ }^{17}$ Despite this evidence, clozapine remains underutilized in general ${ }^{18}$ and in BD in particular, mostly due to tolerability and safety concerns. ${ }^{19}$

The aim of the study was to evaluate the risks and benefits of switching from clozapine to another antipsychotic medication in BD patients with remitted manic, depression, or mixed episodes. The study took advantage of a change in local reimbursement rules which started in 2014, the cost of clozapine was no longer reimbursed for patients with a diagnosis of $\mathrm{BD}$ disorder. This naturalistic study was conducted in the 3rd Clinical Department of Clinical Hospital of Psychiatry and Neurology, Brasov, Romania (an academic unit), according to Good Clinical Practice rules and local regulations. The study was approved by the local Ethics committee (Comisia de Etica). Written informed consent has been obtained from all patients for participation in this study. 


\section{Methods}

\section{Study design}

This is an observational, naturalistic, mirror image study of a cohort of 62 consecutive BD outpatients in remission after severe manic episode treated with clozapine between 2012 and 2014. Clozapine was administered and adverse effects were monitored according to local and international guidelines. Since clozapine never received a regulatory indication for the treatment of $\mathrm{BD}$, in an attempt to control pharmacy costs, in 2014 the health insurance authorities in Romania discontinued reimbursement of clozapine costs for BD patients.

Upon reimbursement discontinuation in 2014, it was explained to patients and their families by the treating psychiatrist that in order to continue treatment with clozapine they would have to pay between $30 € /$ month ( $200 \mathrm{mg} /$ day) and $90 € /$ month ( $600 \mathrm{mg} /$ day) or be switched to another antipsychotic. The risks and the potential benefits of the switch to another antipsychotic were also explained.

Twenty-five patients (40\%) opted to switch to another antipsychotic and the rest remained on clozapine. All switched patients were tapered during a 4 week period. In the switched group the first choice for replacing clozapine was quetiapine ( $\mathrm{n}=10,40 \%)$ with a mean dose of $640 \mathrm{mg} /$ day (average between 400-800 mg/day). The rest of the antipsychotics used for switching are presented in Table 1. In both groups (switched and non-switched), the augmentation of antipsychotic treatment included: mood stabilizers (sodium valproate), benzodiazepines (diazepam and lorazepam), hypnotics (zopiclone, zolpidem, clonazepam, and nitrazepam), and/or addition of a second antipsychotic (haloperidol and levomepromazine). The patients were evaluated with the help of Young Mania Rating Scale (YMRS), ${ }^{20}$ MontgomeryÅsberg Depression Rating Scale, ${ }^{21}$ and Clinical Global Impression for Bipolar Disorder (CGI-BP) ${ }^{22}$ by two boardcertificated psychiatrists. The socioeconomic status was also evaluated and data included the total income per family, number of rooms per person, and the number of persons who supported the patient's treatment.

Table I The antipsychotics used for switching

\begin{tabular}{ll}
\hline Antipsychotics & $\mathbf{n}(\%)$ \\
\hline Haloperidol & $4(19.04)$ \\
Olanzapine & $3(14.28)$ \\
Quetiapine & $10(47.6 \mathrm{I})$ \\
Risperidone & $2(9.52)$ \\
Amisulpride & $\mathrm{I}(4.76)$ \\
Aripiprazole & $\mathrm{I}(4.76)$ \\
\hline
\end{tabular}

\section{Statistical analysis}

Demographics and severity scores before and after clozapine switching were compared using the variance ratio test $(F$-test). Statistical significance was set at two-sided $P<0.05$.

\section{Results}

Of the 62 patients included in this study, 37 (59.7\%) continued clozapine (non-switched group). The rest, 25 (40.3\%), were switched to another antipsychotic (switched group). Demographics and results of the switch are shown in Table 2. The mean score of CGI-BP at admission in study was similar in both groups ( 2.3 vs 2.4 , respectively). After switching, a significant proportion of patients relapsed $(\mathrm{n}=21.0,84.0 \%)$, 13 men and 8 women. In all cases the relapse episode was manic and patients required hospitalization. The mean YMRS score at relapse was significantly higher compared with the evaluation at the time prior to switching (31.78 standard deviation $[\mathrm{SD}]=9.72$ vs $11.99 \mathrm{SD}=7.29, P<0.01$ ). As shown in the Table 2 more switched patients were hospitalized and exacerbated than patients who continued on clozapine.

According to the local prescribing protocol for $\mathrm{BD}$, the patients were switched to: olanzapine, quetiapine, risperidone, aripiprazole, and haloperidol. One patient continued treatment with amisulpride. The antipsychotics used after clozapine switching are presented in Table 2 . There was no statistical difference between second generation antipsychotics (SGAs) and haloperidol regarding the time until relapse or in the SGAs group. The decision to switch to a specific antipsychotic was made by the psychiatrist based on his individual preference.

\section{Discussion}

The major finding of this study was that replacing clozapine with another antipsychotic might lead to an increased risk in relapse and hospitalization in remitted BP patients.

The use of clozapine on- and off-label and the apparent under-utilization of clozapine remains a controversial issue in clinical psychiatry. ${ }^{18}$ Besides treatment-resistant schizophrenia, the only other indication approved by regulatory authorities (US Food and Drug Administration) for clozapine is for suicide prevention in schizophrenia. ${ }^{23}$ Nevertheless, and despite the lack of randomized controlled studies, clozapine is used off-label for the treatment of aggression in patients with $\mathrm{BD}$, intermittent explosive disorder, post-traumatic stress disorder mental retardation, manifestations of personality disorder and agitation in dementia. ${ }^{16,24-31}$ Furthermore, clozapine use reduced psychiatric hospitalization and emergency room visits, numbers and length of psychiatric admissions, and psychotropic comedications, in patients with $\mathrm{BD} .{ }^{15,32}$ 
Table 2 Patient demographics

\begin{tabular}{|c|c|c|c|}
\hline Characteristics & $\begin{array}{l}\text { Non-switched group } \\
n=37,59.7 \%\end{array}$ & $\begin{array}{l}\text { Switched group } \\
n=25,40.3 \%\end{array}$ & P-value \\
\hline Gender, male, $n=36,58.1 \%$ & 23 & 13 & $<0.05$ \\
\hline Age (years) & $38.94(10.59)$ & $38.76(10.17)$ & 0.846 \\
\hline Age of onset (years) & $26.67(8.17)$ & $27.60(7.7 I)$ & 0.782 \\
\hline Duration of illness (years) & $12.00(7.68)$ & II.I6 (5.5I) & 0.091 \\
\hline Number of hospitalizations (lifetime) & $8.67(5.38)$ & $7.60(3.65)$ & 0.049 \\
\hline Days of hospitalizations (lifetime) & $212.56(123.90)$ & $190.20(90.76)$ & 0.113 \\
\hline Clozapine before replacing, months, mean (SD) & $13.91(6.20)$ & $14.32(5.27)$ & 0.408 \\
\hline Remission before clozapine discontinuation (months) & $10.18(5.55)$ & $10.64(4.58)$ & 0.326 \\
\hline Remission after clozapine discontinuation (months) & $12.93(6.24)$ & $9.24(3.90)$ & 0.018 \\
\hline Relapse after clozapine replacing & $8(21.62)$ & $21(77.77)$ & $<0.0001$ \\
\hline Hospitalization after clozapine replacing & $8(24.24)$ & $25(75.76)$ & $<0.0001$ \\
\hline Total amount of money/family & $€ 780$ & $€ 821$ & 0.884 \\
\hline Number of persons who support patient's treatment & 2,3 & 2.1 & 0.921 \\
\hline
\end{tabular}

Note: Data presented as $\mathrm{n}(\%)$ unless stated otherwise.

Abbreviation: SD, standard deviation.

As we know, besides psychotropic medication, many other factors influence illness course and relapse, and many of these are related to socioeconomic circumstances. Switching antipsychotic could be one of these factors (type of switch, low doses, too fast or too slow tapering, less sedative effect for aripiprazole or risperidone, etc.). In our study there was no difference in the total amount of income per family as well as the number of relatives who supported the cost of patient's treatment.

The current study has limitations which are inherent to the naturalistic, non-randomized design, such as the possibility that the patients' and their families' decision not to discontinue clozapine was determined by a perceived likelihood of impending exacerbation which might have affected the outcome. Furthermore, in addition to antipsychotics both groups were treated with additional but different psychotropics, which in turn might have also affected the outcome. Moreover, despite the gradual discontinuation of clozapine, a cholinergic rebound might have occurred in some of the patients. ${ }^{33}$

\section{Conclusion}

In summary, despite the inherent limitations of this study design, it suggests that discontinuation of clozapine in remitted $\mathrm{BD}$ patients should be weighed against the potential risk of symptom exacerbation.

\section{Acknowledgments}

We would like to thank to the staff of the Clinical Hospital of Psychiatry and Neurology Brasov, România, and to Gheorghe Pamfil for assistance with data collection and processing.

\section{Authors' contributions}

Conception and design of the research, PI and AT; acquisition of data, PI and AT; analysis and interpretation of the data, PI,
MAM and AT; writing of the manuscript, PI, MAM, AMP; critical revision of the manuscript for intellectual content, PI, MAM and RSM. All authors contributed toward data analysis, drafting and critically revising the paper and agree to be accountable for all aspects of the work.

\section{Disclosure}

The authors report no conflicts of interest in this work.

\section{References}

1. Goodwin FK, Jamison KR. Manic Depressive Illness. 2nd ed. New York: Oxford University Press. 2007.

2. Baldessarini RJ, Salvatore P, Khalsa HM, et al. Morbidity in 303 first-episode bipolar I disorder patients. Bipolar Disord. 2010;12(3): 264-270.

3. Baldessarini RJ, Vieta E, Calabrese JR, Tohen M, Bowden CL. Bipolar depression: overview and commentary. Harv Rev Psychiatry. 2010;18(3):143-157.

4. Baldessarini RJ. Chemotherapy in Psychiatry. 3rd ed. New York: Springer Press. 2013.

5. Grande I, Berk M, Birmaher B, Vieta E. Bipolar disorder. Lancet. 2016; 387(10027):1561-1572.

6. Tondo L, Baldessarini RJ. Suicide in bipolar disorder. In: Yildiz A, Nemeroff C, Ruiz P, editors. Bipolar Disorder: Millennium Update. New York: Oxford University Press, New York. 2014.

7. Grunze H, Vieta E, Goodwin et al. The World Federation of Societies of Biological Psychiatry (WFSBP) Guidelines for the Biological Treatment of Bipolar Disorders: Update 2010 on the treatment of acute bipolar depression. World Journal of Biological Psychiatry. 11(2): 81-109.

8. Perlis RH, Welge JA, Vornik LA, Hirschfeld RM, Keck PE Jr. J Clin Psychiatry. 2006; 67(4):509-516.

9. Falkai P, Wobrock T, Lieberman J, Glenthoj B, Gattaz WF, Möller HJ; World Federation of Societies of Biological Psychiatry (WFSBP) Task Force on Treatment Guidelines for Schizophrenia. World J Biol Psychiatry. 2005;6(3):132-191.

10. Yatham LN. Acute and maintenance treatment of bipolar mania: the role of atypical antipsychotics. Bipolar Disord. 2003;5(2):7-19.

11. Perils RH, Welge JA, Vornik LA, Hirschfeld RMA, Keck PE Jr. Atypical antipsychotics in the treatment of mania: a meta-analysis of randomized, placebo-controlled trials. J Clin Psychiatry. 2006;67(4):509-516.

12. Calabrese JR, Kimmel SE, Woyshville MJ, et al. Clozapine for treatment-refractory mania. Am J Psychiatry. 1996;153(6):759-764. 
13. Vieta E, Sanchez-Moreno J. Acute and long-term treatment of mania. Dialogues Clin Neurosci. 2008;10(2):165-179.

14. Frye MA, Ketter TA, Altshuler LL, et al. Clozapine in bipolar disorder: treatment implications for other atypical antipsychotics. J Affect Disord. 1998;48(2-3):91-104.

15. Nielsen J, Kane JM, Correll CU. Real-world effectiveness of clozapine in patients with bipolar disorder: results from a 2-year mirror-image study. Bipolar Disord. 2012;14(8):863-869.

16. Ifteni P, Correll CU, Nielsen J, Burtea V, Kane JM, Manu P. Rapid clozapine titration in treatment-refractory bipolar disorder. $J$ Affect Disord. 2014;166:168-172.

17. Li XB, Tang YL, Wang CY, de Leon J. Clozapine for treatment-resistant bipolar disorder: a systematic review. Bipolar Disord. 2015;17(3): 235-247.

18. Bogers JP, Schulte PF, Van Dijk D, Bakker B, Cohen D. Clozapine underutilization in the treatment of schizophrenia: how can clozapine prescription rates be improved? J Clin Psychopharmacol. 2016;36(2): $109-111$.

19. Green AI, Tohen M, Patel JK, et al. Clozapine in the treatment of refractory psychotic mania. Am J Psychiatry. 2000;157(6):982-986.

20. Young RC, Biggs JT, Ziegler VE, Meyer DA. A rating scale for mania: reliability, validity and sensitivity. Br J Psychiatry. 1978;133: 429-435.

21. Montgomery SA, Asberg M. A new depression scale designed to be sensitive to change. Br J Psychiatry.1979;134(4):382-389.

22. Spearing MK, Post RM, Leverich GS, Brandt D, Nolen W. Modification of the Clinical Global Impressions (CGI) Scale for use in bipolar illness (BP): the CGI-BP. Psychiatry Res. 1997;73:159-171.

23. Meltzer HY, Alphs L, Green AI, et al. International Suicide Prevention Trial Study Group. Clozapine treatment for suicidality in schizophrenia: International Suicide Prevention Trial (InterSePT). Arch Gen Psychiatry. 2003;60(1):82-91.
24. Kant R, Chalansani R, Chengappa KN, Dieringer MF. The off-label use of clozapine in adolescents with bipolar disorder, intermittent explosive disorder, or posttraumatic stress disorder. J Child Adolesc Psychopharmacol. 2004;14(1):57-63.

25. Cohen SA, Underwood MT. The use of clozapine in a mentally retarded and aggressive population. Journal of Clinical Psychiatry. 1994;55(10): 440-444.

26. Antonacci DJ, de Groot CM. Clozapine treatment in a population of adults with mental retardation. J Clin Psychiatry. 2000;61(1):22-25.

27. Frankenburg F, Zanarini M. Clozapine treatment of borderline patients: a preliminary study. Compr Psychiatry.1993;34:402-405.

28. Benedetti F, Sforzini L, Colombo C, Maffei C, Sameraldi E. Low dose clozapine in acute and continuation treatment of severe borderline personality disorder. J Clin Psychatry. 1998;59:103-107.

29. Beri A, Boydell J. Clozapine in borderline personality disorder: a review of the evidence. Ann Clin Psychiatry. 2014;26(2):139-44.

30. Lee HB, Hanner JA, Yokley JL, Appleby B, Hurowitz L, Lyketsos CG. Clozapine for treatment-resistant agitation in dementia. $J$ Geriatr Psychiatry Neurol. 2007;20(3):178-82.

31. Bastiampillai T, Dhillon R, French TH. Clozapine use in treatmentresistant agitation in the setting of dementia. Aust NZJ Psychiatry. 2009; 43(7):689-690.

32. Wu CS, Wang SC, Liu SK. Clozapine use reduced psychiatric hospitalization and emergency room visits in patients with bipolar disorder independent of improved treatment regularity in a three-year follow-up period. Bipolar Disord. 2015;17(4):415-423.

33. Shiovitz TM, Welke TL, Tigel PD, et al. Cholinergic rebound and rapid psychosis following abrupt clozapine withdrawal. Schizophr Bull. 1996; 22(4):591-595.
Neuropsychiatric Disease and Treatment

\section{Publish your work in this journal}

Neuropsychiatric Disease and Treatment is an international, peerreviewed journal of clinical therapeutics and pharmacology focusing on concise rapid reporting of clinical or pre-clinical studies on a range of neuropsychiatric and neurological disorders. This journal is indexed on PubMed Central, the 'PsycINFO' database and CAS,

\section{Dovepress}

and is the official journal of The International Neuropsychiatric Association (INA). The manuscript management system is completely online and includes a very quick and fair peer-review system, which is all easy to use. Visit http://www.dovepress.com/testimonials.php to read real quotes from published authors. 